\title{
Knowledge, Perception and Practice of Safety Measures Related to Workplace Hazards among Manual Stone Crushing Workers in Sokoto, Nigeria
}

\author{
Kaoje Aminu U1', HaliruLadan'1, Raji Mansur O'1, Ango Umar M¹, Ango Jessica T ${ }^{1}$ \\ ${ }^{1}$ Department of Community Health, Usmanu Danfodiyo University, Sokoto, Nigeria. \\ Kaoje Aminu U, FWACP; Department of Community Health, Usmanu Danfodiyo University, Sokoto, Nigeria. \\ Haliru Ladan, MBBS; Department of Community Health, Usmanu Danfodiyo University, Sokoto, Nigeria. \\ Raji Mansur O, FWACP; Department of Community Health, Usmanu Danfodiyo University, Sokoto, Nigeria. \\ Ango Umar M, FWACP; Department of Community Health, Usmanu Danfodiyo University, Sokoto, Nigeria \\ Ango Jessica T, FWACP; Department of Community Health, Usmanu Danfodiyo University, Sokoto, Nigeria
}

\section{ABSTRACT}

Background: Although manual stone crushing activities provide income to families, the working conditions are often unhealthy and dangerous and employees are ignorantly exposed to different hazardous materials particularly dust particles.

Objectives: To assess Knowledge, perception, and Practice of occupational safety measures related to workplace hazards among manual stone crushing workers.

Methods: A descriptive cross-sectional study was conducted among 156 informal small-scale quarries for construction materials workers in Sokoto metropolis. The respondents were selected using a simple random sampling technique and data collected using interviewer-administered questionnaires. Descriptive, bivariate and binary logistic regression analyses were performed using Statistical Package for Social Sciences version 23 and results presented in tables.

Results: Respondents median age was 23 years, interquartile range: $18.3-28.0$. Adolescents and young adults accounted for $54.4 \%$ of the workforce. All the respondents were males and $69.9 \%$ had no formal education. Only $25 \%$ had good knowledge of workplace hazard and as high as $63 \%$ have a low-risk perception of the hazards. Very few $(7.7 \%)$ reported the use of personal protective equipment. Only awareness of disease risk $(\mathrm{aOR}=5.25$, $\mathrm{P}<0.001)$ was the predictor of respondents' knowledge of workplace hazards. Predictors for risk perception level of workplace hazards were respondents' knowledge $(\mathrm{aOR}=0.33, \mathrm{p}<0.01)$; Aware of risk of disease $(\mathrm{aOR}=2.92$, $\mathrm{P}<0.01$ ); and employment status ( $\mathrm{aOR}=0.31, \mathrm{p}<0.03)$.

Conclusions: Poor knowledge and low-risk perception of workplace hazards are very prevalent among workers and very few reported use of personal protective equipment. Training and awareness creation on workplace hazards are highly recommended.

Key words: Knowledge; Manual stone crushing; Risk perception; Safety practice; Workplace hazards

DOI: https://doi.org/10.3126/ijosh.v8i1.22923

\section{Introduction}

W

orkplace exposure to dust is a well-known and a common phenomenon especially in developing

\section{Corresponding Author}

Kaoje Aminu Umar,

Department of Community Health,

Usmanu Danfodiyo University (UDU) Sokoto Nigeria,

E-mail:umar.aminu1@udusok.edu.ng

(c) 2018 IJOSH All rights reserved countries, despite documented adverse effects of ambient air pollution with particulate matter. ${ }^{1,2}$ Numerous stone-crushing industries and individuals in developing countries generate a lot of airborne particulate matters and these workers are often ignorantly exposed to these dust. ${ }^{3}$ Dust particles ranges from 1 to $100 \mu \mathrm{m}$ in diameter and when deposited in lungs they have the potential to cause harm either locally or elsewhere in the body. ${ }^{4}$ 
Primitive hand tools such as digger and hammer are still used by the workers for quarrying stones while burning fire and rarely explosives are used to disintegrate large stone which is then broken into smaller stones by the same tool. ${ }^{5-7}$ In the developed world, sophisticated methods are now being employed in quarry industries, which are either gasoline or electric driven engines, tractors and heavy-duty vehicles. ${ }^{7}$

Airborne particulates pose a potential health risk to quarry employees in the form of respiratory, dermal, and ocular irritation. ${ }^{8-10}$ Chronic exposure to dust in stone cutting Industry may increase the risk of respiratory problems and impaired lung function; cigarette smokers, long duration of work and non usage of Personal Protective Equipment (PPE) are at higher risk. ${ }^{11}$ Of serious concern is the inhalation of dust containing silica, which can lead to silicosis, an irreversible lung disease which progresses even when exposure stops. ${ }^{9}$ Accidents and injuries, hearing loss, dust-related lung diseases are also of major concerns among stone cutting workers. However, all of these diseases and health-related conditions can be prevented; the working conditions improved with simple means and minimal cost. ${ }^{12}$

A study in Zaria Nigeria revealed that as large as twothirds of quarry workers were aware of the need to use safety devices and also to institute safety/preventive measures at the worksites, despite their low level of education. Yet, all of the workers had a history of one form of occupational hazard or another such as respiratory symptoms $(64.9 \%)$, cuts from the stones $(68.9 \%)$, eye irritations $(14.9 \%)$, and skin irritations by $10.8 \%$ of the study respondents. ${ }^{13}$

In Nigeria, manual stone crushing provides a source of employment to different categories of people including under-age children, yet it is unrecognized and unregulated by the government. Though it provides some financial stability, employees working conditions are often risky and dangerous. The crushed stones are used for the construction of buildings mostly by lowincome that cannot afford machine crushed stones. A large proportion of dust and particulate matters generated is within their breathing zone which makes them easily inhalable, especially when not wearing facemask or respirator. It is within this background the study was conducted to assess workers knowledge, level of risk perception to workplace hazards and practice of occupational safety measures.

\section{Methods}

The study was conducted in Sokoto metropolis of the State. Sokoto Metropolis comprised of four local government areas (LGAs). Sokoto state is located in the northwest region of Nigeria, within latitude $12^{\circ}$ South and $13^{\circ} 58^{\prime}$ North and longitude $4^{\circ} 8^{\prime}$ East and $60-54^{\circ}$ East and has a land area of $26,648.48 \mathrm{~km}^{2}$. It is bordered to the North by the Niger Republic, East by Zamfara state and Kebbi state to the South and West. There were estimated three hundred manual stone crushing workers distributed in all the 35 informal small-scale manual rock crushing sites within the metropolis. At nearly all the sites, rudimentary tools such as hoes, pickaxes, chisels, and shovels; coupled with labor intensive activities like digging, breaking, panning, sorting and carrying by hand are the common features. A descriptive cross-sectional study was conducted among 156 informal manual rock quarrying workers operating within Sokoto metropolis between 15 $5^{\text {th }}$ December 2017 and April 23rd, 2018. Criteria for inclusion in the study were being a regular worker in the sites, voluntarily consented to participate and were present at the time of data collection otherwise no reason for exclusion. The outcome variables were knowledge and risk perception of workplace hazards whereas the independent variables included respondents' socio-demographic characteristics and other work-related factors. Knowledge of workplace hazards, risk perception and consistent use of personal protective equipment were calculated primarily using sources from a previous publication. Primary data to measure the outcome variables were obtained from the respondents. Structure questionnaire with closeended questions was used to collect the data through a face-to-face interview. The questionnaires were pretested on the quarry workers from sites not part of the main study.

A required sample size was determined using formula for descriptive cross-sectional study design for population less than ten thousand, ${ }^{14} \mathrm{n}_{\mathrm{f}=} \mathrm{n} / 1+(\mathrm{n} / \mathrm{N})$ and $n=Z^{2}{ }_{\alpha} \times p q / d^{2}$ where ' $n_{f}$ ' is required sample size; $n=$ Minimum sample size desired; $Z_{\alpha}=$ Standard Normal deviate corresponding to significance level at $\alpha$ error of $5 \%=1.96 ; \mathrm{N}=$ total study population (population of informal quarry workers in this case in study area = 300); $p=$ Prevalence of factor under study as reported in the previous study in Benin which was $74.1 \%,{ }^{15} \mathrm{q}=$ complimentary probability of factor under study (1-P) and $d=$ tolerable alpha error or level of precision $=5 \%$. 
Substituting the values in second formula above, $\mathrm{n}$ $=\left(1.96^{2} \times 0.741 \times 0.259\right) / 0.05^{2}=295$. Since the study population is less than 10,000 , then the required sample size, $n_{f}$ was determined by substituting the values in $n_{f=} n /[1+(n / N)]=295 /[1+(295 / 300)]=149$

For the expected potential attrition due to a poorly filled questionnaire or misplacement, the attrition factor was added (assuming attrition rate of $10 \%$ ) which translated to a sample size of 165 (149/0.9). Multistage sampling method (balloting technique) was used to select the respondents.

The responses on respondents' knowledge of workplace hazards were scored and graded. Each correct response of knowledge was scored 1 mark while zero (0) was awarded to wrong answers and no-response. The knowledge was graded as either good or poor knowledge. Knowledge scores less than $50 \%$; equal to or greater than $50 \%$ were adjudged poor and good knowledge respectively. Respondents' risk perception was categorized as either low or high. An appropriate response on perception question was scored one mark while inappropriate responses zero mark. Overall percent score of less than $70 \%$; equal to or greater than $70 \%$ was adjudged as low risk and highrisk perceptions respectively. The associations were examined in these two categories with independent exploratory variables.

Data were analyzed using statistical package for social science (SPSS) version 23.0. Median and interquartile range was used to summarize respondents' age while the categorical data were expressed in frequency, proportion, and percentage. Chi-squared test of association was performed to evaluate the relationship between the outcome variables (knowledge and risk perception level of workplace hazards) and respondents' socio-demographic characteristics and some work-related factors. Binary logistic regression analysis using forced entry method was carried out to identify key factors influencing respondents' knowledge and level of risk perception to workplace hazards. The 95\% confidence interval $(\mathrm{Cl})$ was computed around the adjusted odds ratio. Level significance was set at $p<0.05$. Ethical clearance was sought and obtained from the Health Research Ethics Committee of Sokoto state Ministry of Health. In addition, individual consent was obtained from the respondents before questionnaires were administered.

\section{Results}

Respondents' median age was 23 years, with interquartile range (IQR) 18.3 - 28.0. Adolescents and young adults aged 24 years and below accounted for $54.4 \%$ of the workforce. All the respondents were males and also Muslims. The majority $(70 \%)$ of the respondents had no formal education and $24 \%$ had primary education. While $55 \%$ reported cigarette smoking, $16 \%$ admitted the use of stimulant drugs, none of the respondents reported consumption of alcohol. Half of the workers earned between N500 to $\mathrm{N} 1,500$ daily. Only $13 \%$ have worked for greater than 10 years and less than $30 \%$ of them work for greater than eight hours daily. (Table 1)

Only $25 \%$ of the respondents' demonstrated good knowledge of workplace hazards and only $24 \%$ knew the hazards could cause or predispose you to diseases or injuries. Only $33 \%$ knew that wearing personal protective equipment can help reduce the risk from these hazards and nearly half (48\%) also know that taking some times off duty will help reduce the effect of a hazard on the body. Most mentioned hazard was stone dust and particles, followed by stone crushing tools themselves by $49 \%$ and then sharp objects on site like rocks, sticks by $28 \%$. (Table 2 )

Nearly two-thirds of respondents have a low perception of risk of their workplace. Less than a quarter perceived that workplace hazards can predispose them to injury and infection and $43 \%$ felt the injury could severe and fatal. About two-thirds believe dust emanating from stone crushing may contain harmful chemical, 52\% perceived nonuse of PPE could increase the risk of injury and almost half felt underage children should not be allowed to come close to the stone crushing area. (Table 3)

Only $12 \%$ of the respondents were ever informed by the site owner/colleagues to use PPE. And of these proportions, only one person each reported always use of facemask, utility hand gloves, and rubber boot while none use eye goggles always. About one third were not using PPE because they could not afford to buy, $16 \%$ feel uncomfortable if they wear PPE while $17 \%$ do not use PPE because of they always careful when at the site or crushing stone. Almost half of the respondents reported ever sustaining an injury while on site but only $9 \%$ went to the chemist for proper treatment. (Table 4) 
Knowledge, Perception and Practice of Safety Measures Related to Workplace Hazards among Manual Stone ...

The prevalence of work-related injuries were $76.9 \%$ and $64 \%$ of the workers sustained bleeding injuries. Categories of these injuries include cuts from sharp rocks, crushing injury from working tools or stone, skin abrasion, and low back pain. Nearly two-thirds graded the injury as mild while only $25 \%$ graded their injury as being severe. (Table 5 )
The chi-squared test of association analysis showed that employment status $\left(X^{2}=10.41, d f=1, P<0.001\right)$; and being aware of the risk of diseases $\left(X^{2}=29.64, d f=1\right.$, $p<0.001$ ) had statistically significant association with respondents 'knowledge of workplace hazards whereas age, marital status and educational level did not show statistically significant association. (Table 6)

Table 1: Socio-demographic characteristics of the manual stone crushing workers $(n=156)$

\begin{tabular}{|c|c|c|c|}
\hline Variables & Frequency & Percentage & Median, IQR \\
\hline \multicolumn{4}{|l|}{ Age groups (years) } \\
\hline $14-18$ & 28 & 17.9 & \\
\hline $19-24$ & 57 & 36.5 & \\
\hline $25-39$ & 64 & 41.0 & \\
\hline $40-60$ & 7 & 4.4 & \\
\hline Average age of the respondents & & & 23 years, $18.3-28.0$ \\
\hline \multicolumn{4}{|l|}{ Marital status } \\
\hline Married & 47 & 30.1 & \\
\hline Single never married & 109 & 69.9 & \\
\hline \multicolumn{4}{|l|}{ Educational level } \\
\hline No formal education & 109 & 69.9 & \\
\hline Primary & 37 & 23.7 & \\
\hline Secondary & 8 & 5.1 & \\
\hline Tertiary & 2 & 1.3 & \\
\hline \multicolumn{4}{|l|}{ Social life } \\
\hline Smoke cigarette & 86 & 55.1 & \\
\hline Use addictive drugs & 25 & 16 & \\
\hline \multicolumn{4}{|l|}{ Employment status } \\
\hline Employed by the site owner & 29 & 18.6 & \\
\hline Self-employed & 127 & 81.4 & \\
\hline \multicolumn{4}{|l|}{ Job Description } \\
\hline Breaking of large rocks & 87 & 55.8 & \\
\hline Crushing rock into pieces & 115 & 73.7 & \\
\hline Loading crushed pieces into vehicles & 117 & 75.0 & \\
\hline \multicolumn{4}{|l|}{ Daily earning (Naira) } \\
\hline$\leq 340$ & 14 & 9.0 & \\
\hline $341-1000$ & 89 & 57.5 & \\
\hline$>1000$ & 52 & 33.5 & \\
\hline Average daily earnings (Naira) & & & N1000, IQR 500-1500 \\
\hline \multicolumn{4}{|l|}{ Duration of Working (years) } \\
\hline$<5$ & 68 & 43.6 & \\
\hline $5-10$ & 68 & 43.6 & \\
\hline$>10$ & 20 & 12.8 & \\
\hline Average duration of working & & & 5 years, IQR $2.0-9.8$ \\
\hline \multicolumn{4}{|l|}{ Daily working hours } \\
\hline$\leq 8$ & 111 & 71.2 & \\
\hline$>8$ & 45 & 28.8 & \\
\hline Average daily working hours & & & $7.1 \pm 2.6$ hours \\
\hline
\end{tabular}


Kaoje Aminu U et al.

Table 2: Knowledge of some aspect of hazards associated with stone crushing

\begin{tabular}{|c|c|c|}
\hline Variables & Frequency & Percentage \\
\hline \multicolumn{3}{|l|}{ Respondents' General knowledge scores } \\
\hline Good knowledge & 39 & 25.0 \\
\hline Poor knowledge & 117 & 75.0 \\
\hline \multicolumn{3}{|c|}{ What are some of the hazards in your workplace: } \\
\hline Stone dust and particles & 132 & 84.6 \\
\hline Stone crushing tools & 77 & 49.4 \\
\hline Sharps object like rocks, sticks.t.c. & 43 & 27.6 \\
\hline Biting and stinging insects & 41 & 26.3 \\
\hline Excessive heat from the sun & 34 & 21.8 \\
\hline Microorganisms & 6 & 3.8 \\
\hline \multicolumn{3}{|c|}{ Human organ most seriously affected by the quarry work } \\
\hline Lung & 89 & 38.4 \\
\hline Eyes & 80 & 34.5 \\
\hline Kidney & 27 & 11.6 \\
\hline Heart & 19 & 8.2 \\
\hline Liver & 17 & 7.3 \\
\hline \multicolumn{3}{|c|}{ Some associated ill health that could arise from this hazard } \\
\hline Back pain & 140 & 15.2 \\
\hline Eye infection & 131 & 14.2 \\
\hline Skin abrasion and infection & 131 & 14.2 \\
\hline Crushing injury from working tools or stone & 127 & 13.8 \\
\hline Cuts from sharp rocks & 118 & 12.8 \\
\hline Falls & 107 & 11.6 \\
\hline Cough & 58 & 6.3 \\
\hline Chest pain & 53 & 5.7 \\
\hline Shortness of breath & 38 & 4.1 \\
\hline Blood in sputum & 20 & 2.2 \\
\hline
\end{tabular}

Table 3: Level and some aspect of risk perception of occupational hazards in the workplace

\begin{tabular}{lcc}
\hline Variables & Frequency & Percentage \\
\hline Level of risk perception & & 98 \\
\hline Low perception & 58 & 63 \\
\hline High perception & & 37 \\
\hline Some aspect of risk perception & 101 & 64.7 \\
\hline Dust from stone crushing may contain a harmful chemical substance & 82 & 52.6 \\
\hline Nonuse of PPE could increase the risk of injury & 75 & 48.1 \\
\hline Children should not be allowed to come close to a stone crushing area & 75 & 48.1 \\
\hline Taking some times off duty will help reduce the effect of hazard on body & 69 & 44.2 \\
\hline Stone crushers are at increased risk of lung infection at a later age & 67 & 42.9 \\
\hline Injury that could result from these hazards can be severe and fatal & 51 & 32.7 \\
\hline $\begin{array}{l}\text { Wearing personal protective equipment can help reduce the risk from } \\
\text { these hazards }\end{array}$ & 37 & 23.7 \\
\hline These hazards can cause or predispose you to diseases or injuries & & \\
\hline
\end{tabular}


Table 4: Safety practices among manual stone crushing workers

\begin{tabular}{|c|c|c|}
\hline Variables & Frequency & Percentage \\
\hline Ever been informed by site owner or colleague to use PPE & 18 & 11.5 \\
\hline Wear PPEs to protect yourself while on site/crushing stones & 12 & 7.7 \\
\hline \multicolumn{3}{|l|}{ How often do you use these PPEs } \\
\hline \multicolumn{3}{|l|}{ Face Mask } \\
\hline All the time & 1 & 0.6 \\
\hline Most of the time & 4 & 2.6 \\
\hline \multicolumn{3}{|l|}{ Utility Hand Gloves } \\
\hline All the time & 1 & 0.6 \\
\hline Most of the time & 8 & 5.1 \\
\hline \multicolumn{3}{|l|}{ Rubber boot } \\
\hline All the time & 1 & 0.6 \\
\hline Most of the time & 2 & 1.3 \\
\hline \multicolumn{3}{|l|}{ Hat/head cover } \\
\hline All the time & 0 & 0 \\
\hline Most time & 1 & 0.6 \\
\hline \multicolumn{3}{|l|}{ Eye goggles } \\
\hline All the time & 0 & 0 \\
\hline Most time & 2 & 1.3 \\
\hline \multicolumn{3}{|l|}{ What is the main reason you don't use PPE } \\
\hline Could not afford to buy PPE & 51 & 32.7 \\
\hline PPE not provided & 30 & 19.2 \\
\hline Won't injure me because am careful when working & 27 & 17.3 \\
\hline Feel uncomfortable when I wear PPE & 25 & 16.0 \\
\hline PPEs not necessary & 23 & 14.7 \\
\hline
\end{tabular}

Table 5: Common injuries sustained by workers

\begin{tabular}{lcc}
\hline Variables & Freq. & Percent \\
\hline Did you sustain an injury while working here in the last 1 year & 120 & 76.9 \\
Yes & 36 & 23.1 \\
\hline No & & 84.0 \\
What are the categories of the injuries you sustained & 131 & 68.6 \\
\hline Skin abrasion & 107 & 44.9 \\
\hline Slip, trip and falls & 70 & 28.8 \\
\hline Cuts from sharp rocks & 45 & 16.0 \\
\hline Low back pain & 25 & 64.2 \\
\hline Crushing injury from working tools or stone & 77 & 66.2 \\
\hline Sustained bleeding injuries within the last 1 year & & 24.7 \\
\hline What action did you take when you sustained the injury & 51 & 9.1 \\
\hline Apply local concoction & 19 & 7 \\
\hline Arrest the bleeding using a rag & & 70.8 \\
\hline Went to chemist & 85 & 4.2 \\
\hline How will you grade the intensity of injury sustained & 5 & 25.0 \\
\hline Mild & 30 & \\
\hline Moderate & & \\
\hline Severe & & \\
\hline
\end{tabular}


Table 6: Relationship between socio-demographic characteristics and other work-related factors by Knowledge of Workplace Hazards

\begin{tabular}{|c|c|c|c|}
\hline \multirow{2}{*}{ Variables } & \multicolumn{2}{|c|}{ Knowledge score } & \multirow[b]{2}{*}{ Test statistics and $p$ value } \\
\hline & Poor & Good & \\
\hline \multicolumn{4}{|l|}{ Age group (years) } \\
\hline $14-17$ & $12(27.9)$ & $16(14.2)$ & \multirow{5}{*}{$\begin{array}{l}\text { Fischer exact test }=7.40 \\
\qquad p=0.09\end{array}$} \\
\hline $18-24$ & $16(37.2)$ & $41(36.3)$ & \\
\hline $25-34$ & $13(30.2)$ & $51(45.1)$ & \\
\hline $35-64$ & $1(2.3)$ & $5(4.4)$ & \\
\hline$\geq 65$ & $1(2.3)$ & 0 & \\
\hline \multicolumn{4}{|l|}{ Marital status } \\
\hline Married & $10(23.3)$ & $37(32.7)$ & \multirow{2}{*}{$\begin{array}{c}X^{2}=1.33, d f=1 \\
p=0.25\end{array}$} \\
\hline Single & $33(76.7)$ & $33(76.7)$ & \\
\hline \multicolumn{4}{|l|}{ Educational level } \\
\hline Qur'anic only & $32(74.4)$ & $77(68.1)$ & \multirow{4}{*}{$\begin{array}{l}\text { Fischer exact test }=1.73 \\
\qquad p=0.6\end{array}$} \\
\hline Primary & $8(18.6)$ & $29(25.7)$ & \\
\hline Secondary & $3(7.0)$ & $5(4.4)$ & \\
\hline Tertiary & 0 & $2(18)$ & \\
\hline \multicolumn{4}{|l|}{ Employment status } \\
\hline Employed by site owner & $15(34.5)$ & $14(12.4)$ & \multirow{2}{*}{$\begin{array}{c}X^{2}=10.41, d f=1 \\
P<0.001\end{array}$} \\
\hline Self-employed & $28(65.1)$ & $99(87.6)$ & \\
\hline \multicolumn{4}{|l|}{ Aware risk of disease } \\
\hline Yes & $14(32.6)$ & $89(78.8)$ & \multirow{2}{*}{$\begin{array}{c}X^{2}=29.64, d f=1 \\
p<0.001\end{array}$} \\
\hline No & $29(67.4)$ & $24(21.2)$ & \\
\hline
\end{tabular}

The chi squared test of association analysis showed that only age (Fischer exact test $=11.89, \mathrm{p}=0.01$ ); knowledge of work place hazards $\left(X^{2}=20.9, d f=1\right.$, $\mathrm{p}<0.001)$; awareness of risk of diseases $\left(X^{2}\right.$ $=22.91, \mathrm{df}=1, \quad \mathrm{p}<0.001)$ and employment status $\left(X^{2}\right.$ $=12.9, \mathrm{df}=1, \quad \mathrm{p}<0.001)$ have statistically significant association with risk perception level. The chi squared test of association analysis showed that only age (Fischer exact test $=11.89, p=0.01$ ); knowledge of work place hazards $\left(X^{2}=20.9, d f=1, p<0.001\right)$; awareness of risk of diseases $\left(X^{2}=22.91, d f=1, p<0.001\right)$ and employment status $\left(X^{2}=12.9, d f=1, p<0.001\right)$ have statistically significant association with risk perception level. (Table 7)

Respondents' awareness of the risk of disease significantly predicted whether they would have poor or good knowledge (aOR $=5.25, \mathrm{P}<0.001$ ). The odds ratio tells us that as the awareness level changes by a unit, the changes in the odds of having low knowledge compared to high knowledge are 5.25. Respondents who are aware of the risk of disease from workplace hazards are 5.25 more likely to have good knowledge of the hazards.
Respondent knowledge did significantly predict whether they will have low or high-risk perception of workplace hazards, $(\mathrm{aOR}=0.33, \mathrm{p}<0.01)$. The odds ratio tell us that as knowledge changes from poor to good, the changes in the odds of having low perception compared to high perception is 0.33 . Respondents with good knowledge are 3.0 times more likely to have low workplace hazards risk perception level.

Awareness of risk of disease also did significantly predicted whether the respondents will have low risk rather than high-risk perception (aOR $=2.92, \mathrm{P}$ $<0.01$ ). The odds of having low risk rather than highrisk perception are 2.92, so the respondents who are aware that there is a risk of disease from the hazards are nearly 3 times more likely to have high-risk perception index. Respondents' employment status also did significantly predicted whether they will have a low or high-risk perception index of workplace hazards, $(\mathrm{aOR}=0.31, \mathrm{p}<0.03)$. The odds of having low risk rather than high-risk perception index is 0.31 , so the quarry workers employed by the site owners were 3.2 times more likely to have poor knowledge of workplace hazards. (Table 8) 
Knowledge, Perception and Practice of Safety Measures Related to Workplace Hazards among Manual Stone ...

Table 7: Statistical analysis between variable and the risk perception level

\begin{tabular}{|c|c|c|c|}
\hline \multirow{2}{*}{ Variables } & \multicolumn{2}{|c|}{ Risk Perception Level } & \multirow[b]{2}{*}{ Test Statistic \& P Value } \\
\hline & Low & High & \\
\hline \multicolumn{4}{|l|}{ Age Groups (years) } \\
\hline $14-17$ & $15(26.3)$ & $13(13.1)$ & \multirow{5}{*}{$\begin{array}{l}\text { Fischer exact test=11.89, } \\
\qquad p=0.01\end{array}$} \\
\hline 18-24 & $24(42.1)$ & $33(33.3)$ & \\
\hline $25-34$ & $17(29.8)$ & $47(47.5)$ & \\
\hline $35-64$ & 0 & $6(6.1)$ & \\
\hline$\geq 65$ & $1(1.8)$ & 0 & \\
\hline \multicolumn{4}{|l|}{ Marital status } \\
\hline Married & $13(22.8)$ & $34(34.3)$ & \multirow{2}{*}{$\begin{array}{c}X^{2}=2.29, d f=1 \\
p>0.13\end{array}$} \\
\hline Single & $44(77.2)$ & $65(65.7)$ & \\
\hline \multicolumn{4}{|l|}{ Knowledge score } \\
\hline Poor & $28(49.1)$ & $15(15.2)$ & \multirow{2}{*}{$\begin{array}{c}X^{2}=20.9, d f=1 \\
p<0.001\end{array}$} \\
\hline Good & $29(50.9)$ & $84(84.8)$ & \\
\hline \multicolumn{4}{|c|}{ Awareness of risk of disease } \\
\hline Yes & $24(42.1)$ & $79(79.8)$ & \multirow{2}{*}{$\begin{array}{c}X^{2}=22.91, d f=1 \\
p<0.00\end{array}$} \\
\hline No & $33(57.9)$ & $20(20.2)$ & \\
\hline \multicolumn{4}{|l|}{ Educational level } \\
\hline Qur'anic only & $39(68.4)$ & $70(70.7)$ & \multirow{4}{*}{$\begin{array}{c}\text { Fischer exact test }=1.16, p= \\
0.85\end{array}$} \\
\hline Primary & $15(26.3)$ & $22(22.2)$ & \\
\hline Secondary & $3(5.3)$ & $5(5.1)$ & \\
\hline Tertiary & 0 & $2(2.0)$ & \\
\hline \multicolumn{4}{|l|}{ Employment status } \\
\hline Employed by site owner & $19(33.3)$ & $10(10.1)$ & \multirow{2}{*}{$\begin{array}{c}X^{2}=12.9, d f=1 \\
p<0.001\end{array}$} \\
\hline Self-employed & $38(66.7)$ & $89(89.9)$ & \\
\hline
\end{tabular}

Table 8: Predictors of respondents Knowledge of and risk perception of Workplace Hazards

\begin{tabular}{|c|c|c|c|}
\hline Variable & $P$ value & OR & $95 \% \mathrm{Cl}$ \\
\hline \multicolumn{4}{|l|}{ Factors for Knowledge } \\
\hline Awareness of risk of disease & 0.0001 & 5.25 & $2.27-12.14$ \\
\hline \multicolumn{4}{|c|}{ The reference category: Good Knowledge } \\
\hline \multicolumn{4}{|l|}{ Factors for risk perception } \\
\hline Knowledge & 0.01 & 0.33 & $0.14-0.79$ \\
\hline Awareness & 0.01 & 2.92 & $1.23-6.66$ \\
\hline Employment mode & 0.03 & 0.31 & $0.10-0.91$ \\
\hline \multicolumn{4}{|c|}{ The reference category: High-risk perception } \\
\hline
\end{tabular}

$\mathrm{OR}=$ Odds ration; $\mathrm{Cl}=$ Confidence interval

\section{Discussion}

Nowadays, mostly in the developing countries, poverty and lack of earning jobs have succeeded in exposing community members in the rural areas and in particular the adolescent into dangerous occupations with consequent significant health impacts due to hazardous process, materials and environmental conditions associated with such occupations. ${ }^{16}$ This study found that more than half of the respondents were adolescent and young adults and most of them never had a formal education with prevalent practice of cigarette smoking and use of addictive drugs. Education provides employment opportunities and helps households and individuals to break the chain of poverty. Lack of education denied many of the youths responsible employment and because of consequential poverty, they are pushed to engage in all kind of dangerous jobs like this one that may require them to take drugs for extra energy and to be able to cope with job demand. Being a small-scale informal activity and no qualification required of personnel at all levels of the operation, allows employers and parents to employ children for parts of the work to 
increase the family income. However, International Labour Organization stated that child labor in mining and quarrying is in virtually all cases, a Worst Form of Child Labour because of the extent and severity of the hazards and the risks of death, injury, and disease. It is backbreaking work and there is no justification poverty included - for children to work in this sector. It is literally. ${ }^{17}$

A study in Zaria reported a similar trend where $69.9 \%$ of manual quarry workers had no formal education, more than half smoke cigarette, and $16 \%$ use addictive drugs. ${ }^{13}$ The similarities are attributed to the fact that both areas share common socio-cultural characteristics. Implications are that they continue to use such drugs and are likely to influence the majority others into smoking and drugging. Although, Ebonyi in southeastern Nigeria and India are socio-cultural different from the study respondents, a significant proportion of employee was reported to have no formal education respectively. ${ }^{18,19}$ Manual stone crushing seem exclusively left for those referred to as illiterate because it's low earning and does not break the circle of poverty among those that engage in the occupation.

A very large proportion of the respondents in the study do not have insight into different hazards inherent in their workplace. Although diverse health issues affecting the workers were identified and enumerated, some which included back pain, eye irritation/infection, skin abrasion/infection crushing injury, cuts from sharp objects, and cough, yet all these could not be attributed to exposures in the work environment by the workers. Low knowledge of workplace hazards and risks could arise from the fact that vast majority can never read nor write and manual quarrying are not regulated in this part of the world. This will continue to expose them to the hazards especially the dust and small stone particles and crushing injuries from the working tool. Cumulative exposure to dust and particles may likely lead to pneumoconiosis and other obstructive airway diseases due to chemical constituents of some of the rocks. Most of the pneumoconiosis that may develop is irreversible and many of those likely exposed are an adolescent who is expectedly the backbone of productivity and growth of a society. Therefore the vicious circle of poverty is likely to persist and lack of growth and development increased burden of chronic obstructive airway diseases and increases burden to already stretched health system as the vast number of youths will be affected.
Although in a lower scale, the categories of healthrelated sign and symptoms were consistent with the findings in studies in Zaria ${ }^{13}$, Ebonyi ${ }^{18}$, and India. ${ }^{16}$ This could be attributed to exhaustion due to musculoskeletal disorder and long hours of work. A study from Zaria Nigeria that reported similar physical injuries and accidents among quarry workers revealed that long work-hours, long exposure time to hazards at the workplace and musculoskeletal disorder such as backache, weakness, joint pain and muscular pain from repeated movements, stress and strain and carrying heavy loads may likely be contributed to high proportion of injury. ${ }^{20}$ Most of musculoskeletal disorders are likely to continue as a chronic injury that may transform to debilitating injury at old age if appropriate preventive and control measures are ignored by workers.

Knowledge of workplace hazard, awareness of the disease risk from the hazards and engagement mode of workers at the quarry site influences their perception of risk. However, those with good knowledge are 3 times more likely to have low-risk perception and workers employed by the site owners were 3.2 times more likely to have low-risk perception level. The owner is very likely not provide information of hazards inherent in the workplace to their worker in order not scare them away or obliged to provide PPE to every worker which is likely to reduce their profit margin. Sir Thomas Morison Legge, the first Medical Inspector of Factories and Workshops in the United Kingdom works was especially concerned with anthrax and lead poisoning. He made some proposition called Legge aphorism with respect to workplace safety. He said 'Unless and until the employer has done everything - and everything means a good deal - the workman can do next to nothing to protect himself although he is naturally willing enough to do his bit; If you can bring an influence to bear external to the workman (i.e. one over which he can exercise no control), you will be successful; and if you can't or don't, you won't; Practically all industrial lead poisoning is due to the inhalation of dust and fumes; and if you stop their inhalation you will stop the poisoning; and All workmen should be told something of the danger of the materials they come into contact with and not be left to find it out for themselves sometimes at the cost of their lives'. ${ }^{21}$ Stone crushing is necessary in order to build roads, bridges, buildings and almost everything we need in our modern life, but everyone employed by these industries be it small scale is expected to exercise and demonstrate the highest level of safety in the workplace at all times. 
Accidents and injuries, hearing loss, dust-related lung diseases although preventable, if the working conditions are improved and workers comply, are some of the serious concern in stone crushing. ${ }^{12}$ Use of personal protective devices which were the last resort for the workers as there were no administrative and engineering controls measures, was at zero levels as only very few were found using the safety gadgets, which was not regular. Although many indicated intent to use personal protective equipment for low earning from the job that is just adequate for a daily meal, there are constraints in obtaining their personal devices. Site owners, who are the employer of labor, are supposed to provide PPEs, provide training on how to use the PPE and ensure that workers wear the equipment properly and at all times. Unfortunately, they are not educated to appreciate the benefits of the devices and since the occupation is informal and not regulated by the government they do not fulfill these obligations and laborers who are also ignorant of health consequences of non-use are left alone. Similar experienced was reported in a Study where it was found that the owners of the crushing stone unit never provide appropriate measures to protect the workers thus increasing the high incidence of non-protection from the dust. ${ }^{22}$ The study in Ebonyi, Nigeria revealed more disturbing findings as less than $2 \%$ of the respondent quarry worker use $\mathrm{PPEs}^{18}$, while about one third were reported to use PPE in Edo. ${ }^{19}$ Although these items do not remove the workplace hazards but provide a barrier between the worker and the hazards, there will be no direct physical contact or exposure to the hazards and this lead to a significant reduction in the amount of dose of dust particle that will be inhaled through the respiratory system into the lung and other related injuries. This will significantly reduce the number of an individual that may sustain injuries and or develop diseases from the cumulative effect of inhaled dust particles. The very poor use of PPE among workers might be responsible for the high prevalence of work-related injuries, of which the majority were bleeding injuries. Individuals

\section{References}

1. Bakke PS, Hanva R, Gulsvik A. Relation of occupational exposure to respiratory symptoms and asthma in a general population samples: selfreported versus interview-based exposure data. Am J Epidemiol 2001; 154: 477-483. who are highly susceptible to particular disease or injury are likely to take precautionary measures.

Different types of rocks with varied chemical constituents are crushed manually into various sizes and dust and airborne particulates are produced in sizeable quantity. There is a need for further studies that will focus on dust and blood analysis of the quarry workers for different heavy metals poisoning like silica. Also to carry out spirometry and chest radiography to assess if these are consistent with respiratory symptoms reported by the respondents. This will help for early detection and proper case management to promote reversal of the clinical course of consolidating lung diseases as a result of exposure to the particulates.

Very few respondents had good knowledge of workplace hazards and similarly, low proportion expressed highrisk perception of the hazards, with resultant poor utilization of personal protective equipment (PPE) for their safety. This is of serious public health concern to the state because of the potential burden of occupational lung disorders. The significant number of respondents who had experienced respiratory symptoms evidences this. There is a strong need to create awareness on workplace hazards and on the benefit of using PPE for the safety of the occupational group. The government should also regulate the manual stone crushing activities as its current hub for child labor and provide a medium for imitating adolescent drug use and addition.

\section{Acknowledgment}

We wish to acknowledge the kind support of the study respondents for their time and ideas and also the research assistant, data clerks who maintained quality assurance during the process of data collection and data entry into computer statistical software.

\section{Conflict of interest}

The authors have no conflict of interest associated with the conduct of the study and with all the materials presented in this article.
2. Aigbedion I. and lyayi S. Environmental effect of mineral exploitation in Nigeria. Int. J. Phys. Sci., 2: 33- 8, 2007.

3. Fatusi A, Erbabor G. Occupational health status of sawmill workers in Nigeria. In Ugbogu OC, Ohakwe $\mathrm{J}$ and Foltescu V. African Journal of Respiratory Medicine. March 2009. Pg 23. 
4. World Health Organization. Prevention and control exchange: Hazard prevention and control in the work environment. Geneva: WHO, 1999; pp 219.

5. Mathur ML, Choudhary RC. Mortality experience of sand stone quarry workers of Jodhpur district. Lung India. 1996; 14 (2): 6668.

6. Mathur ML. Pattern and Predictors of Mortality in Sandstone quarry workers. Indian J Occup Environ Med.2005; 9 (2): 80-85. 6

7. Chan CN, Chan SY. Silicosis a preventable occupational disease. J Hong Kong Med Assoc. 1994; 46 (1): 3136.

8. Urom SE, Antai AB, Osim EE. Symptoms and lung function values in Nigerian men and women exposed to dust generated from crushing of granite rocks in Calabar, Nigeria. Niger J Physiol Sci. 2004; 19 (1-2): 4147.

9. Ugbogu OC, Ohakwe J, Foltescu V. Occurrence of Respiratory and Skin problems among manual stone quarrying workers. African Journal of Respiratory Medicine.2009; 23-26.

10. Isah EC, Okojie OH, Edet E. Artisanal manual stone quarrying in a rural community of Edo State, Nigeria: implication for occupational health. JMBR. 2004; 3 (2): 4955 .

11. Hatim MJ, Mona SM, Amal ME, Omaima KE, Hanan MI, Waleed SE. Pulmonary Problems among Stone Cutting Workers in West Bank-Palestine. Med. J. Cairo Univ. 2015; Vol. 83, No. 1: 769-775.

12. Angotzi L, Bramanti D, Tavarini M, Grag-Nani L, Cassiodoro L, Moriconi, P et al. World at work: Marble quarrying in Tuscany. Occup. Environ. Med., 62: 417-21. doi: 1.1136/oem.2004.018721, 2005.

13. Aliyu AA, Shehu AU. Occupational Hazards and Safety Measures among Stone Quarry Workers in Northern Nigeria. Niger Med Pract 2006;2:42-7.

14. Araoye OM. Research methodology with statistics for Health and Social Sciences. Ilorin, Mathadex Publishers.2003: 423.
15. Aigbokhaode $A Q$, Isah $E C$, Isara $A$ : Knowledge and Practice of Occupational Safety among Quarry workers in a rural community in Edo State. Journal of Community Medicine and Primary Health Care.2011, Vol. 23, (1\&2).

16. Semple S, Green DA, McAlpine M, Cowie H, Seaton A. Exposure to particulate matter on an Indian stonecrushing site. Occupational and Environmental Medicine. May 2008; Vol. 65, No. 5, pp. 300-305.

17. International Labour Organization. Eliminating Child Labour in Mining and Quarrying. International Programme on the Elimination of Child Labour (IPEC).World Day Against Child Labour. June 2005.

18. Nwibo AN, Ugwuja El, Nwambeke NO, Emelumadu OF, Ogbonnaya LU. Pulmonary Problems among Quarry Workers of Stone Crushing Industrial Site at Umuoghara, Ebonyi State, Nigeria.The International Journal of Occupational and Environmental Medicine.2012;3:178-185.

19. Rajnarayan R, Tiwar I, Yashwant KS, Habibullah NS. Tuberculosis among workers exposed to free Silica dust.Indian Journal of Occupational and Environmental Medicine. August 2007;11 (2).

20. Sufiyan MB, Ogunleye OO. Awareness and compliance with use of safety protective devices and patterns of injury among quarry workers in Sabon-Gari Local Government Area, Kaduna state Northwestern Nigeria. Annals of Nigerian Medicine. 2012, Volume 6, Issue 2: 65-70.

21. Thomas ML. "Thirty Years' Experience of Industrial Maladies". Shaw Lectures. Royal Society of Arts. Chemical News and Journal of Industrial Science. 1929. Volumes 139-140. Page 169.

22. Ilyas Mand Rasheed F. Health and environment related issues in stone crushing in Pakistan. Paper presented at the 10th Round Regional Research Competition of South Asia Network of economic Research Institute (Sanei). 2010. 